\title{
Filologia e Língua Portuguesa: histórico
}

\section{LYGIA CORREA DIAS DE MORAES}

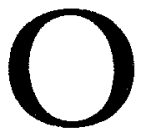

s primeiros documentos sobre a cátedra de Filologia Portuguesa, notadamente o relatório O ensino da Lingua Portuguesa perante as necessidades universitárias do Brasil, com que o professor Rebelo Gonçalves, primeiro responsável por ela, atendia ao pedido da Diretoria da recém-criada Faculdade de Filosofia, Ciências e Letras, de um parecer sincero, não só sobre as deficiências encontradas na organização da Faculdade e no preparo dos alunos, como também sobre os rumos a dar ao ensino ministrado", são ao mesmo tempo um diagnóstico da situação do ensino de língua portuguesa ( $e$, de certa forma, também das humanidades) na ocasião, em São Paulo, e uma proposta de açáo sobre ele, como eixo de uma orientaçáo geral e, conseqüentemente, de um programa de estudos que fosse atingir o ensino em outros níveis, igualmente necessitado de uma reforma (1).

Concordando implicitamente com a opiniăo de seu colega de Filologia e Literatura Grega e Latina, professor Michel Berveiller, que, por sua vez, acusava a heterogeneidade de preparo dos alunos, Rebelo Gonçalves faz a análise crítica do ensino da língua portuguesa nos vários graus, vendo como principais fatores do estado em que a encontrava, primeiro, a persistência da tradição de estudos retóricos e da memorização; depois, a oposição entre gramática expositiva, pouco científica, e gramática histórica; falta de um bom ensino de latim, para o necessário confronto entre as duas línguas; má qualidade na orientaçăo como na organização das antologias escolares. Daí faz decorrer a necessidade de nova base escolar, nos graus anteriores, para um bom ensino superior. $\mathrm{E}$, acentuando, nesse contexto, o preceito de que todos os professores fossem exemplo de perfeição "oral ou literária da língua que falam ou escrevem", permite a inferência de que, a seu ver, os professores brasileiros falavam e escreviam mal.

A proposta final é a de intercâmbio científico entre Brasil e Portugal, para o que já fizera aprovar pelo Centro de Estudos Filológicos de Lisboa o projeto de uma gramática luso-brasileira. Percebem-se, subjacentes, duas diretrizes que iriam, possivelmente, orientar sua atuaçáo no nascente curso de Letras Clássicas: o predomínio, como padrão, da 
variante européia da língua portuguesa e a atribuição do papel central aos estudos filológicos, isto é, de uma abordagem predominantemente histórica no estudo da língua.

Para os dois anos que the concedia o currículo de Letras Clássicas (no $3^{2}$ ano cederia o lugar à Literatura Luso-Brasileira) apresenta um programa de Filologia Portuguesa coerente e bastante abrangente. Inicia-se este com uma seção intitulada Gramática prática, em que consta o exame de alguns aspectos fundamentais da língua (é de supor que sob uma visáo sincrônica). Segue-se a Gramática histórica, com noçốes fundamentais, no $1^{\mathrm{O}}$ ano, e fonética, morfologia, sintaxe e sematologia no $2^{\circ}$. O $1^{\circ}$ ano tem ainda História do português literário e dialetal e Estudo dos elementos do léxico português, continuado por Lexicologia, no $2^{\circ}$, no qual constam ainda comentários de textos, conferências e dissertaçōes escolares.

Em 1937, voltando à França o professor Berveiller, Rebelo Gonçalves assume a cadeira de Filologia e Literatura Grega e Latina e deixa Filologia Portuguesa para o professor Othoniel Mota. Nesse mesmo ano publica em São Paulo dois livros, Filologia e literatura, mais voltado para temas clássicos, e Dissertafốes camonianas.

Os estudos de Português, na Faculdade de Filosofia, Ciências e Letras, nasciam, pois, sob a égide da Filologia, tomada quer em seu sentido vulgar, de dedicação aos estudos de gramática, quer no também corrente de estudo diacrônico da língua, quer no mais amplo, de estudo de uma cultura através de seus textos escritos, o que implica as duas primeiras acepçóes e a liga necessariamente a outras ciências, ampliandolhe vastamente $o$ âmbito.

Essa inclinação marcaria forte e longamente a área, que ainda hoje leva essa designação - Filologia e Língua Portuguesa -, a que faz jus.

Ao assumir, Othoniel Motta era já então conhecido autor de alguns excelentes livros didáticos, Liçôes de Portugués, com que introduziu no Brasil, em 1915, o depois largamente difundido (e, infelizmente, mal usado) método de análise sintática por diagramas que fora tomar aos americanos Reed e Kellog; Seleta moderna e $O$ meu idioma, a que juntava, em 1937, Horas filológicas, estudos com elogiosa apresentação de Rebelo Gonçalves.

Othoniel Motta retomou, em linhas gerais, os programas de seu antecessor.

Em 1939, abre-se o concurso para provimento da cátedra. Apresentaram-se três candidatos, dentre os quais saiu vencedor o professor 
Francisco Silveira Bueno, que ocuparia o lugar por cerca de trinta anos, até a aposentadoria compulsória.

Autodidata na área, com forte hase clássica por formação - tendo sido seminarista, chegara ao curso superior de Teologia -, professor na Escola Normal da praça da República (então Escola Normal Modelo), era autor de uma série de livros didáticos, como Páginas floridas, de cuja seleçáo de textos, geralmente completos e náo apenas fragmentos, guardo uma das boas lembranças de meu tempo de ginásio. A ela se juntavam manuais, como $A$ arte de dizer, $A$ arte de escreper, $A$ arte de falar $\mathrm{em}$ puiblico, a que iriam somar-se outros, todos eles com boa aceitaçáo, a julgar pelo número de ediçóes que tiveram.

A aula inaugural que proferiu em 1940 propóe a concepçáo de Filologia que orientaria seus cursos: ao mesmo tempo arte e ciência pura, a Filologia tem como "objeto principal o conhecimento completo e perfeito da civilização de um povo, numa determinada época de sua vida civil, através das suas obras de razão, de sentimento e de fantasia" (2). O meio é o estudo da língua (entenda-se: histórico, ou diacrônico) e o conhecimento de disciplinas auxiliares para o estudo dos textos. A civilizaçáo de Portugal será, pois, o objeto de estudo da Filologia portuguesa, disciplina sintetizadora de todas as que a isso digam respeito - língua, literatura, história - aplicadas " aos monumentos literários do povo lusitano", para daí "fazer surgir a consciência do conjunto para que cada qual possa ter o seu juízo da civilização lusa, inteirando-se completamente do que foi esse passado tão estreitamente ligado ao nosso presente" (3). A sintaxe, "expressão do pensamento", não interessaria ao lingüista, mas ao filólogo, porque "é na expressáo do pensamento que se encontram as demonstraçóes culturais de um povo, o seu adiantamento literário, o grau de civilização a que já tenha atingido" (4). Com isso, é de supor, o programa alienava-se da realidade lingüística do Brasil. A finalidade do ensino de Filologia no Brasil, porém, seria, ainda a seu ver, preparar professores de língua portuguesa.

Os programas seguem essa orientação, como mostra o Relatório da cátedra de 1953: começando pelas noçóes básicas da história da língua, passam pela formação histórica do português, seguem pelo estudo da língua arcaica, até Gil Vicente e, na época clássica, chegam a Sá de Miranda e Camôes. $O$ ano de especialização, facultativo, mais tarde transformado em $4^{\circ}$ ano, versava sobre estilística, ou podia variar de ano para ano. A bibliografia inclui lingüistas e filólogos das primeiras décadas do século, como Jespersen, Meillet, Vendryès, Marouzeau, Bourciez, Williams (5). 
Para atender às necessidades do curso publicou, a partir de 1946, outras obras, como Estudos de filologia portuguesa, em que condensava suas aulas; Tratado de semantica brasileira, causa de polêmicas, notadamente com O Estado de S. Paulo, pela pena de Paulo Duarte; Estilistica brasileira e outros, além de dicionários e uma Gramática normativa da língua portuguesa (de 1944). Organizou ainda um laboratório de fonética (1951), de cujos trabalhos não deixou notícia, senáo no relatório desse ano, e um Jornal de filologia, revista cujo primeiro número é de 1953.

Apesar das diretrizes de seu programa inicial, Silveira Bueno não se ateve ao estudo da norma do português de Portugal, freqüientemente ilustrando as aulas com exemplos tomados ao português falado no Brasil. Delas guardei uma recomendaçáo que me valeu na prática do ensino de gramática, "Comecem sempre pelo exemplo, nunca pela regra!", indicando o método indutivo, sem dúvida o melhor, no caso.

Contraditoriamente, porém, sua Gramática normatipa pauta-se pela norma culta de Portugal: a exemplificação se faz, sobretudo, por autores clássicos portugueses. Dos brasileiros, poucos, com preferência por Machado de Assis, ainda que afirme nas Palapras necessárias com que apresenta a gramática: "para isto devemos dar maior atenção aos fatos de hoje, explicando-lhes a evolução, aparando as demasias dos que querem correr de mais e dos que se esforçam por voltar às eras anteriores ao descobrimento do país" (p. $\mathrm{x}$ ).

Ou pelas condiçóes de trabalho que tinham entáo os professores da Faculdade, com turmas grandes (reuniam-se em suas aulas, quando ainda não tinha assistentes, as das três secçôes de Letras), ou pela própria personalidade, o professor Silveira Bueno não incentivava os alunos à pesquisa, nem mesmo a exigia deles.

Como conseqüência, são muito poucas as teses defendidas durante seu tempo de cátedra. A primeira, de 1944, é de aluna da primeira turma da Faculdade. Outras poucas (duas de doutorado, uma de livre-docência) vêm nas décadas de 50 e 60 . A substituiçăo dos cursos de Especialização pelos de Pós-Graduação (regime antigo), na de 60, não dá mostra de ter alterado muito o quadro (6).

Aposentando-se o professor Silveira Bueno, foi chamado a assumir a área, de que pouco adiante viria a ser titular, o professor Segismundo Spina, livre-docente da cadeira de Literatura Portuguesa e nela criador da disciplina de Camonologia, mas com trabalhos e apaixonado interesse em Filologia. 
A época era a da Reforma universitária, 1969. A Faculdade crescera: dos três alunos da turma de Letras Clássicas de 1934 e dos vinte e cinco do meu tempo, as classes de Filologia e Língua Portuguesa haviam chegado a mais de duzentos, em alguns casos, nas precárias acomodaçôes dos barracos - as oitocentas e cinqüenta vagas para Letras incluíam todas a habilitação em Português - e poucos e heróicos professores, situação mais tarde alterada pela regulamentaçáo das vagas e pela vinda de mais professores, mas que hoje nova reforma dos currículos trouxe de volta.

Era um tempo de grandes inquietações, de anseio por mudanças. Era também o de interesse máximo pela lingüística, sobretudo em sua vertente estruturalista. Reformaram-se os currículos e programas, procurando-se adequá-los com objetividade à finalidade dos cursos: preparar pesquisadores $\mathrm{e}, \mathrm{em}$ maior número, professores de português para o ensino médio. Os programas da graduação passaram a apoiar-se na moderna lingüística, sem se fazerem, contudo, de lingüística aplicada ao português, mas de língua portuguesa sobre fundamentação lingüística. A diferença está na direção do enfoque.

Partindo do estudo do texto (recepção e produção) como objeto primeiro de análise, os programas passam pela morfossintaxe e pela estilística, chegando aos processos da língua falada e abrangendo, ainda, o estudo diacrônico da língua e a iniciaçáo à filologia. Evidentemente, o progresso da ciência, as mudanças nos ângulos de observaçáo dos fatos lingüísticos, tanto quanto nas necessidades do preparo dos alunos em vista das exigências de sua formação, levaram a sucessivas reformulaçóes ao longo destes vinte e cinco anos, enriquecendo-os de novas abordagens, quer do texto escrito, quer do oral (objeto de renovada atençáo), quer da análise gramatical. Professores da área vêm publicando livros, geralmente de larga aceitação, tanto para o público universitário como para o de outros níveis.

A Pós-Graduação, pelo regime novo (que se iniciara com apenas três professores da área), foi-se ampliando à medida que se habilitavam os docentes. Atendeu - e atende ainda - a candidatos de todo o país. Incluiu entre seus objetivos o estudo do português do Brasil. Mas foi dos poucos centros que preservaram o interesse (de algum tempo para cá efusivamente renascente em outros) pela filologia: das dissertaçốes e teses defendidas entre 70 e $\mathbf{9 3}$, cerca de $\mathbf{3 8 \%}$ o foram no âmbito desta (7).

O tempo altera as fisionomias. Conservando seus traços fundamentais, a face da área foi-se transformando e enriquecendo. As linhas 
de pesquisa da Pós-Graduação estenderam-se, organizando-se, atualmente, em torno de seis áreas de concentração: Morfossintaxe, Análise do Discurso, Análise da Conversação, Lexicologia e Lexicografia, Lingüística Histórica, Crítica Textual.

Giram em torno dessas linhas vários projetos, quer coletivos, quer individuais. De vida longa, o Projeto NURC/SP, engajado num projeto nacional iniciado por volta de 1970 , recolheu farto material de língua falada, de que transcreveu e publicou um corpus mínimo, usado em diversas teses, terminadas ou em andamento, e que faz parte do corpus da gramática do português falado no Brasil, em elaboração por um grupo que reúne pesquisadores de várias universidades do país. Nas áreas ligadas ao trabalho filológico, os projetos se ligam à produçáo de ediçóes críticas de textos quer modernos, quer antigos, e ao estudo de aspectos gramaticais da língua arcaica. As outras, trabalhando com base na Análise do Discurso, na Análise da Conversação, em abordagens semântico-pragmáticas, examinam textos orais ou escritos, literários, jornalísticos, ou, em outras bases, planejam dicionários e glossários, revêem a gramática.

Ao longo de sua vida, a área de Filologia e Língua Portuguesa foi a responsável, direta ou indireta, pela formação de tantas geraçóes de professores de todos os graus e de pesquisadores de muitos centros. A ela, e a todos os que nela e por ela trabalharam, este artigo homenageia, no sexagésimo aniversário da alma mater, a Faculdade de Filosofia, Ciências e Letras da Universidade de São Paulo.

\section{Referências bibliográficas}

Foram consultados os seguintes volumes do Anutírio da Faculdnde de Filosofin, Ciências e Letras: 1934-1935, 1936 (ambos publicados em 1937), 1937-1938 (publicados em 1938), 1939-1949 (publicação em 1953), 1951 (publicado em 1952) e os Programas aprovados pela Congregafão para os anos de 1953, 1954, 1964, 1965, 1966, todos editados pela Faculdade. Para os anos de $70 \mathrm{em}$ diante, valeram os Programas, geralmente publicados a cada ano letivo e minha própria memória, intimamente ligada a eles.

\section{Notas}

1 Anuirio, 1934-1935, p. 191-197.

2 Anutrio, 1939-1949, v. I, p. 83. 
3 Ibidem, p. 84.

4 Ibidem, p. 85.

5 Programas aprovados pela Congregaçao para o ano letivo de 1953.

6 Conforme catálogo do CAPH - Centro de Apoio à Pesquisa em História - a quem agradeço, na pessoa de sua diretora, Dra Míriam Lifchitz Moreira Leite, pelas informaçōes que me encaminharam às fontes citadas.

7 Segundo a relação fornecida pelo SIBI, possivelmente não de todo completa.

Lygin Corrến Dias de Moraes é professora do Departamento de Letras Clássicas e Vernáculas da Faculdade de Filosofia, Letras e Ciências Humanas da USP. 